\title{
Identifying Proactive Collaboration Strategies for Teacher Readiness For Marginalized Students
}

Imani Akin, Ed.D., University of Phoenix, USA

Crystal Neumann, D.B.A., University of Phoenix, USA

\begin{abstract}
This research discusses the value of collaborating to develop strategies that enhance teacher readiness for the marginalized student and the use of qualitative data that can lead to student academic and social success. Education domains include the learning environment, technology, and building parent and community connections. This research includes data from participants of an educators' professional development workshop regarding the use of appropriate and proactive pedagogical strategies and theories.
\end{abstract}

Keywords: Collaboration; Marginalized Students; Proactive; Strategies

\section{INTRODUCTION}

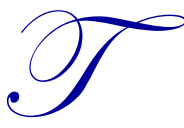

eaching sometimes requires taking risks. Teachers who are risk takers may implement atypical teaching strategies and occasionally may have to defend innovation when lessons are considered nontraditional. The $21^{\text {st }}$ century learner requires nontraditional learning environments and lessons to increase academic success and reduce the number of students who receive specialized services. Reform in teaching and learning is necessary to reduce referral of the $21^{\text {st }}$ century learner for special education services.

According to the U.S. Department of Education (2011), in 2009 13.2\% of learners enrolled in school and aged 3 to 21 received services under the Individual with Disabilities Education Act (National Dissemination Center for Children with Disabilities, 2012). Early identification of at-risk students and response to intervention programs do not reduce the number of students who receive support services. The pace of changes within our society contributes to an increase of students receiving specialized services.

The constant shifts in technology result in a widening of the digital divide and achievement gaps, regardless of the increasing access to technology for many of today's youth. The cultural divide continues even as we move to establish a more global sense of society. The pace of change also affects the homes of many students as they become displaced or disconnected from parents and feel no sense of community. More students are receiving support services in schools for multiple reasons. Proactive collaboration in teaching and learning can reduce specialized services support and enhance teacher skills in providing conducive learning environments, differentiated instruction, and support systems for academic and social success for the $21^{\text {st }}$ century learner.

Current teacher pre-service programs do not emphasize the importance of proactive collaboration that may prevent issues such as teacher reaction to situations that arise from the classroom, nonconducive learning environments for the $21^{\text {st }}$ century learner, and the impact of the use of technology as a curricular tool. Collaborative planning can aid in teachers anticipating classroom situations, introduce teachers to strategies that create appropriate learning environments, and encourage application of technology in student learning activities.

Implications of previous studies include the necessity for the collaboration of education advocates to support teachers of learners with various needs. Internal focus groups and action research can aid educational leaders 
in supporting teachers. Additionally, strategic teams with a focus on effective use of teacher skills can provide inhouse professional development to support teachers of learners with special needs (Akin, 2007).

Teacher reaction to issues that arise out of the classroom can lead to teacher stress and burnout, as well as student stress (Wehby \& Lane, 2009). Reactions can negatively affect student academic and social success, while being proactive can positively affect success. Three focus areas in which educators can be proactive include fostering a safe learning environment, implementing technology into the teaching and learning process, and building partnerships with parents and the community as part of the learning team to circumvent the marginalization of students.

\section{Marginalization of Students}

There are many reasons that students, at some time or another, may become members of a marginalized group (Miller, 2006). The marginalization of a student may be due to cultural differences, knowledge gaps, and socioeconomic status, which result in the need for supplemental support within education learning environments. Identifying and developing collaboration policies and strategies to bridge the transition of marginalized students into the margins of conducive learning environments can also enhance teacher readiness for the marginalized student and lead to student academic and social success. Teacher readiness calls for embracing collaboration in order to contribute to the academic success of marginalized students.

Teachers are the single most important factor in determining student success in school. Cunningham and Gordeiro (2003) suggested that in the real world of school, however, problem solving is not done independently. Therefore, forming collaborative teacher teams to examine student work is best practice. Marshall (2009) discussed the potential synergy of collaboration. The synergy can provide high quality support for students who have academic gaps, come from low socioeconomic households, and have diverse cultural backgrounds. The complexities of the problems that school leaders and classroom teachers address necessitate collaboration. McMurray and Sorrells (2007) suggested that bureaucratization negatively affects student success. Proactive collaboration leads to identifying additional processes, methods of gaining resources, and achieving exemplary outcomes for student success.

\section{LITERATURE REVIEW}

\section{Collaboration}

Idol, Paolucci-Whitcomb, and Nevin (1995) identified collaboration as "an interactive process that enabled individuals with diverse expertise to generate creative solutions to mutually defined problems" (p. ix). An ideal method was to include family members and family systems as collaborative partners. Some professionals faced the demand of adapting to differing expectations and cultures pertaining to professional and family systems. Teachers interpreted patterns that hinder student success and shared this new information with parents, students, and other teachers.

\section{Data Collection for Teachers}

Teachers can collaborate and analyze qualitative data to broaden their teaching. In 2012, Pella decided to make a case for broadening the notion of what is data in education. The study showed how teachers collaborated and analyzed data to broaden the teaching and learning experience in writing for a more rigorous and integrated literacy pedagogy.

The call to use data has been defined in school reform and used to align academic and social programs such as counseling and the school mission (Young \& Kaffenberger, 2011). Strategies were implemented as a result of collecting and analyzing data to lead to increased student performance. Data can also contribute to closing the achievement gap and demonstrating program effectiveness of chosen programs. 
A one-size-fits-all model of instruction is ineffective in promoting student achievement and increasing linguistic diversity. Teacher analysis of observation notes and student classroom work developed a process of sustained data inquiry cycle (Pella, 2012) as well as a cycle of collaboration. A collaborative and consultative model that includes inquiry cycles and contextualized investigation improved teaching practices (Idol, Paolucci-Whitcomb, $\&$ Nevin, 1995). The benefit for the student was the result of equity-oriented pedagogy because the teacher reflected on data and used the new information to develop strategies that act as a bridge to level the playing field among the students. The student has gained academic and social emotion support from the use of qualitative data.

\section{Proactivity and Planning}

Reflective teachers establish a cycle of proactivity to continuously create an enhanced learning experience. When teachers were proactive and planned a conducive learning environment, the plan increased academic engagement and decreased disruptive conduct. When teachers took a proactive approach and observed the classroom dynamics during ideal and non-ideal situations, this helped to develop management strategies that guided student engagement and behaviors during teaching and learning. Planned processes and procedures prevent disruptions or interruptions during instruction. When teachers plan to manage the classroom, students become more engaged in a positive classroom environment (Guardino \& Fullerton, 2010).

It is essential to be in the proactive mindset (Eisen, 2010). Teachers who envisioned, developed, and implemented individual student plans recognized that these are necessary processes for teacher readiness to support marginalized students. With a proactive mindset, the teacher can perform the plan mindfully before any visible changes are made.

\section{Reflective Analysis}

Teachers can assess data to design and develop student plans. Teachers can use the data to interpret meaning and look for emerging patterns and predicators that enhances or hinder student success. Proactive teachers can also assess and reflect on the cross-cultural communication of students and their families. Cultural awareness of the linguistic differences can be the bridge to enhance the student and teacher relationship. Teachers who reflected on personal interaction styles found it to be an essential process in developing a collaborative relationship with the student's family (Lupi \& Tong, 2001). The reflection should be a cycle of data inquiry in order to foster ongoing improvement.

Reflective teachers realize that strategies used in the past may not be appropriate for present or future experiences. Documents such as the Critical Incident Analysis (CIA) tool helped teachers reflect on experiences to plan for future action (Davies \& Kinloch, 2000). Teachers who created a cycle of learning within the process of reflection applied best practice. Teachers can also link specific incidents with knowledge from outside sources to put into action. This transfer of new knowledge into an action plan is the result of the interpretation of student data.

Qualitative data collection is significant to the teaching and learning process because data can be interpreted and educators can design an appropriate plan of action for the student (Gillanders, Mason, \& Ritchie, 2011). However, existing school data can be used to improve instruction. With data analysis, teachers can examine information that may emerge as predictive of student success and use these success patterns to assist other students. Teachers who reflect on what worked and what did not work make adjustments and create new practices that contribute to student success.

\section{METHODOLOGY}

The purpose of this qualitative, phenomenological study was to explore the perspectives and experiences from teachers and staff who support students with special needs and who are at risk of being marginalized. A phenomenological design was used to gain a better comprehension of the phenomenon being studied (Moustakas, 1994). The answers were evaluated by common themes documented by the order of significance. This research includes data obtained from a statewide educator professional development workshop. In the professional development workshop, nine educators participating in a focus group were asked the definition of their experiences 
with collaboration and practicing proactivity. The educators were given a case study and qualitative data to analyze and asked to design a plan of action to support the student's academic and social needs. Pella (2012) noted that some education specialists such as Linda Darling Hammond recognized the collection of qualitative data within a method of inquiry cycle as scholarly and a transition toward transformational teaching practices.

\section{Research Design and Appropriateness of Design}

The quantitative method was not appropriate for the study because quantitative research would not answer the questions of how or why. Focus groups allow for follow-up questions and probing (Salkind, 2003). The goal of the study was to obtain an understanding of the way things are, why they are that way, and what respondents perceive and experience. Qualitative analysis provides a deeper understanding of the phenomenon by analyzing words (Creswell, 2005). The purpose of this research was to gain a better understanding of the phenomenon of teachers' and educational staff's perception of proactive collaboration, which led to forming a semi-structured focus group and asking open-ended questions.

\section{Population}

The population of the study consisted of nine educational staff and K-12 teachers. The teachers have an average of 8 years teaching experience. All participants in the study are employees of urban and suburban schools in the state of Illinois, which adhere to the same state professional and learning educational standards.

\section{Data Collection}

Data were collected and validated through a semi-structured focus group to obtain information in the participants' own words. In addition to an entrance and exit ticket, the participants were given a case study to review to help guide the discussion (see Appendix A). Participants were given data tools such as a collaboration template (Appendix B) to track their discussion and decisions regarding the case study. The research consisted of organizing, analyzing, and synthesizing the data from the focus group into coded responses based on emerging themes (Salkind, 2003). A systematic reduction led to significant themes that were central to the phenomenon.

The two research questions guiding this study were:

- R1: What student data can be used to identify collaboration strategies to enhance new teacher skills and knowledge to work with marginalized students?

- $\quad$ R2: How can patterns of behavior of low socioeconomic or marginalized students and their families be used to develop proactive collaboration strategies for student success?

These essential questions are important because early identification of at-risk students and response to intervention programs do not reduce the number of students referred to special education. Proactive collaboration can reduce response to intervention (RTI) support and enhance teacher skills in differential instruction for student success.

\section{DATA ANALYSIS}

Participants were able to reflect on personal and collective meaning of proactive collaboration. Respondents started with identifying proactive strategies for student academic and social and success. Giving information and sharing resources was mentioned by 5 of the participants. Part of sharing information would involve team meetings, reaching out to parents, planning, and anticipating as well as asking questions.

Similarly, collaborative strategies were identified as having regular team meetings by 7 of the participants. A team meeting could include sharing resources and information with other teachers and staff, parents, and the student. One third of the participants suggested that student-to-student collaboration could occur. Older students can reach out to younger students in a mentoring relationship. 
After discussing proactive and collaborative strategies, the focus group worked together to develop academic and social strategies to support marginalized students inside and outside of the classroom. Using the tools and prompts provided, the participants developed a plan consisting of four strategies, as shown in Tables 1 through 4.

Participants of the study suggested that collaboration with other teachers, parents, and students would be a strong indicator for success (Table 1). Teachers can work with other teachers or administration to determine the student's behavior in other classes, as well as previous successes within those classes, failures, and how each situation was approached. Through each behavior, the team can determine patterns. For example, the participants discussed using strength-based methods to build a student's confidence.

Teachers should also work with students' parents and the students themselves. In doing so, teachers can better decipher what the home life is like. Teachers can then determine whether any home life factors may contribute to behaviors in school and offer a better understanding as to how to improve their approach.

Table 1: I will plan to...

\begin{tabular}{|l|l|c|}
\hline$(\mathbf{n}=9)$ & \multicolumn{1}{|c|}{ I will plan to } & Number of Participants \\
\hline & Collaborate with team (net) & 4 \\
\hline & Share data tools with teachers & 2 \\
\hline & Learn more about home life and school behaviors from parent/student & 3 \\
\hline & Other (Get more information/Consider cultural factors) & 2 \\
\hline
\end{tabular}

As noted in Table 1, a teacher may collaborate with other teachers and parents to better determine an approach to contribute to a student's success (also see Table 2). However, participants also suggested working with a community representative for collaboration. An example of a community representative would be a former success story, in which this person may be a former student who went through similar experiences and portrayed similar behaviors. In working with a family, this person can provide ideas and explain his or her own lived experience to produce similar successful results. Another example of a community representative would be someone who could provide parent support, such as counseling.

Table 2: I will collaborate with. . .

\begin{tabular}{|l|l|c|}
\hline$(\mathbf{n}=9$, Sigma = 18) & \multicolumn{1}{|c|}{ I will collaborate with } & Number of Participants \\
\hline & Parent & 9 \\
\hline & Teacher & 5 \\
\hline & Community Representative & 4 \\
\hline
\end{tabular}

The participants of this study also expressed using specific tools to help guide them in the collaboration experience. Participants discussed sharing observations and other data such as surveys and school information from administration (see Table 3). A collaboration template could be used to piece all the information in a central location to perform the data assessment and data analysis.

Table 3: I will begin to use. . .

\begin{tabular}{|l|l|c|}
\hline$(\mathbf{n}=\mathbf{7})$ & \multicolumn{1}{|c|}{ I will begin to use } & Number of Participants \\
\hline & Observations & 3 \\
\hline & Collaboration Template & 2 \\
\hline & Other data (surveys, school information) & 2 \\
\hline
\end{tabular}

As shown in Table 4, participants thought that the data assessment/analysis could be used in a variety of ways. Many of the participants determined that the analysis could help drive their strategies. The strategies would include different approaches to help the student grow academically. Other participants determined that the analysis could help with their planning on how to help the student and how to plan their instruction for the class. One participant also noted that he or she would use the analysis with the problem-solving team. 
Table 4: I will use the data assessment/analysis to drive my. . .

\begin{tabular}{|l|l|c|}
\hline$(\mathbf{n}=9$, Sigma = 14) & \multicolumn{1}{|c|}{ I will use the data to } & Number of Participants \\
\hline & Strategies & 4 \\
\hline & Plan & 3 \\
\hline & Instruction & 1 \\
\hline
\end{tabular}

\section{DISCUSSION}

Our research indicated that collaboration was a strong indicator of success, as evident by the participants' shared responses. Answers from the participants led to insight that the collaboration template could also be used for the data analysis when determining strategies. The research of Williamson, Archibald, and McGregor (2010) suggested that success is strongly influenced by the shared concerns of the collaborators. The study of successful writing strategies for students emerged as an in-depth research project that includes the emergence of collaboration prerequisites. A shared vision is a strong prerequisite.

There are many definitions of collaboration that attempt to capture the concept and complexity of interprofessional collaboration. Proactive collaboration in schools can aid in a study of factors that may contribute to student marginalization and the necessary support strategies (Walther-Thomas, Korinek, \& McLaughlin, 1999). The study can also identify patterns that lead to academic gaps and identify predictors for academic success of marginalized students. The patterns and predictors can assist in the development of proactive collaborative strategies for student and teacher school readiness as well as parental and community involvement for academic success. The participants' analysis of student data can lead to understanding the categories of collaboration necessary for student and teacher readiness for effective teaching and learning relationships.

\section{Teacher Readiness and Support}

The participants also identified, instructional and activity issues that arise out of the classroom that contribute to inappropriate behavior. Wehby and Lane (2009) discussed the particularly high attrition rates in special education classes. Educational leaders can use proactive collaboration to offset high rates of teacher turnover that occur. Teacher attrition is not beneficial to students or teachers. Our research supports providing teachers with evidence-based strategies that can be embedded into academic instruction that can enhance the use of appropriate behavior in the classroom from students.

Participants in this study addressed student behavior in a non-punitive manner. According to Clunies-Ross, Little, \& Keinhuis (2008), exceptional teachers do not spend much time on behavior issues in the classroom. Proactive teachers anticipate student behavior and utilize professional collaboration time or professional development time to analyze student academic and behavioral data. Issues such as teacher readiness are addressed in addition to the emergence of classroom and community level factors for student success (Wallace, Anderson, \& Bartholomay, 2002).

\section{Learning Environments}

Participants approached problem solving for the case study in Appendix A by using a strength-based model that focused on her strong math skills to build student confidence. McFarlane (2011) supported differentiated instruction and application of the Multiple Intelligences theory as an instruction approach for a classroom of diverse learners. A conducive learning environment evolves out of teacher choices of instruction, arrangement, and development of processes and procedures for the diverse population of $21^{\text {st }}$ century learners. Howard Gardner's (2006) theory of Multiple Intelligences (MI) proposed that people have gifts and skills that educators can use to enhance the teaching and learning process. Knowing the diverse learner includes recognizing students' learning styles within the classroom and the application of differential instruction to address these multiple learning styles. Through differentiating instruction, the teacher can target a particular area of development of a specific student. 


\section{Partnering with Community and Parents}

Participants' discussions included providing parental support to increase the students' success. As education is a social process, forming partnerships within the community and with parents to enhance and support student learning leads to success for all. Collaborating with parents in the teaching and learning process can be arranged in various ways. Participant interviews have suggested school socials, outside learning opportunities, and parent projects. Interview of business managers gave insight into new and enhanced collaboration practices (Neumann \& Akin, 2012). Current practices such as shadowing, classroom lectures, and internships still contribute to the teaching and learning process. New practices, from interviews with business managers, include suggestions of building communication skills in texting, and the creation of technology labs instead of computer labs prior to developing a learning zone.

\section{Social Media and Technology}

An example of a best practice strategy and an ideal method of driving collaboration would be through the use of social media and technology. Preparations for the 21st century learner consist of knowing how to implement technology into instruction as well as teaching and learning activities. Creating conducive learning environments for the $21^{\text {st }}$ century learner includes consideration of the impact of the use of technology as a curricular tool. The use of technology for teaching and learning may be a necessary method of connection to collaborating with the parents in the development of appropriate student education plans. With the excessive use of technology, comes the need to monitor our children's use of social media. Padilla and Coyne (2011) suggested that we examine and consider the child and the parental factors when monitoring media usage and activities. Technology is a critical skill for the $21^{\text {st }}$ century learner and teacher. The teaching and learning that occurs in the classroom requires the use of technology in instruction and learning activities.

\section{CONCLUSION}

The constant changes in our world and society may contribute to the marginalization of students. The fastpaced changes of technology, as well as culture and language differences that may cause educators, students, and parents to struggle with communication, can impact student academic success. In addition, socioeconomic status may affect the motivation levels of parents and students and impact teaching and learning. Additionally, the diagnosis of learning disabilities may contribute to students needing and receiving services that may result in placement within special groups. Proactive planning will allow teachers to take risks using various strategies and learning environments that support marginalized students.

The learning environment is a critical element of a teacher's readiness for teaching all students. Marginalized students require a sense of belonging and a safe place to learn. Proactive planning to foster a learning place with these requirements is critical in preparing for the socialization of learning. Teacher collaboration with the community and parents will aid in identifying appropriate strategies for student success, relationship building, and maintaining the necessary sense of community for a conducive learning environment.

Effective teachers and effective teaching require readiness for differentiated instruction for all students. Teachers who learn to use data to identify criteria for patterns that lead to academic gaps and identify predictors for academic success will become effective educators as the knowledge of students and family enhance the teaching and learning process and the student-teacher relationship. The patterns and predictors can also be categorized and used in the development of individual student frameworks for proactive communication, and instructional and social strategies for student success. The utilization of differentiated instruction as a result of identified proactive collaborative strategies is an application of teaching and learning that can equal a win-win situation in schools and provide opportunities for equity-oriented pedagogy with the classroom.

Previous teacher studies involve the necessity for the collaboration of education advocates to support teachers of marginalized students. Teacher needs include positive learning environments, community support, and increased use and guidance in technology and data assessment literacy. Proactive collaboration may address the lack of resources, time, and training for teachers who support marginalized students. 
Implications of this study for educational leaders include the use of student data to improve education services on a local, state, and federal level. Suggestions include developing a collaboration model to pilot to a diverse group of educators to assist in determining overall effectiveness. Knowledge of this process can generate a framework for professional development and enhanced teacher skills that contribute to student success.

\section{AUTHOR INFORMATION}

Dr. Akin is associate faculty for the college of education at the University of Phoenix. E-mail: imaniakin@ hotmail.com (Corresponding author)

Dr. Neumann is currently chair of the school of business at the University of Phoenix Indianapolis campus.

\section{REFERENCES}

1. Akin, I. (2007). The effects of teacher perceptions on student placement in restrictive Environments: A grounded theory study. (University of Phoenix). Proquest dissertation and theses.192.

2. Clunies-Ross, P., Little, E., \& Keinhuis, M. (2008). Self-reported and actual use of proactive and reactive classroom management strategies. Educational Psychology, 28(6), 693-710. doi: $10.1080 / 01443410802206700$.

3. Creswell, J. W. (2005). Educational research. Planning, conducting, and evaluating quantitative and qualitative research. Upper Saddle River, NJ: Pearson.

4. Cunningham, W. G., \& Gordeiro, P. A. (2003). Educational leadership: A problem-based approach. Boston, MA: Allyn \& Bacon.

5. Davies, H., \& Kinloch, H. (2000). Critical incident analysis: Facilitating reflection and transfer of learning. In V.E. Cree \& C. Macaulay (Eds.), Transfer of learning in professional \& vocational education, A handbook for social work trainers (pp. 137-147). London, UK: Routledge.

6. $\quad$ Eisen, B. (2010). Be more proactive. Personal Excellence, 15(3), 1-2.

7. Gardner, H. E. (2006). Multiple intelligences: The theory in practice. New York, NY: Basic Books.

8. Gillanders, C., Mason, E., \& Ritchie, S. (2011). First school--Approach that prepares Pre-K to 3 educators to effectively interpret and respond to school data. Young Children, 66(6), 12-19.

9. Guardino, C. A., \& Fullerton, E. (2010). Changing behaviors by changing the classroom environment. Teaching Exceptional Children, 42(6), 8-13.

10. National Dissemination Center for Children with Disabilities. (2012). IDEA: The Individuals With Disabilities Education Act Washington, DC: Author. Retrieved from http://nichcy.org/laws/idea

11. Idol, L., Paolucci-Whitcomb, P. \& Nevin, A. (1995). The collaborative consultation model. Journal of Educational and Psychological Consultation, 6(4), 347-361.

12. Lupi, M., \& Tong, V. (2001). Reflecting on personal interaction style to promote successful cross-cultural school-home partnership. Preventing School Failure, 45(4), 162-166.

13. Marshall, K. (2009). Rethinking teacher supervision and evaluation: How to work smart, build collaboration, and close the achievement ap. San Francisco: Jossey Bass.

14. McFarlane, D. A. (2011). Multiple intelligences: The most effective platform for global $21^{\text {st }}$ century educational and instructional methodologies. College Quarterly, 14(2), 8.

15. McMurray, A., \& Sorrells, D. (2007). Student services and the college classroom: Some ideas for collaboration. College Student Journal, 41(4), 1218-1223.

16. Neumann, C., \& Akin, I. (2012). Collaborating to transition postsecondary students into the workplace. American Technical Education Association Journal, 40(1), 18-12.

17. Miller, M. (2006). Where they are: Working with marginalized students. Educational Leadership, 63(5), 50-54.

18. Moustakas, C. (1994). Phenomenological research methods. Thousand Oaks, CA: Sage.

19. Padilla, L. M., \& Coyne, S. M. (2011). "Turn that thing off!" Parent and adolescent predictors of proactive media monitoring. Journal of Adolescence, 34(4), 705-715.

20. Pella, S. (2012). What should count as data for data driven instruction? Toward contextualized data inquiry models for teacher education and professional evaluation. Middle Grades Research Journal, 7, 57-75.

21. Salkind, N. (2003). Exploring research (5th ed.). Upper Saddle River, NJ: Prentice Hall. 
22. U.S. Department of Education, National Center for Education Statistics (2011). Chapter 2: Elementary and secondary education. Digest of Education Statistics, 2010 (NCES 2011-015). Retrieved from http://nces.ed.gov/programs/digest/d10/ch_2.asp

23. Wallace, T., Anderson, A. R., \& Bartholomay, T. (2002). Collaboration: An element associated with the success of four inclusive high schools. Journal of Educational \& Psychological Consultation, 13(4), 349382. doi: 10.1207/S1532768XJEPC1304_05.

24. Walther-Thomas, C., Korinek, L., \& McLaughlin, V. L. (1999). Collaboration to support students' success. Focus on Exceptional Children, 32(3), 1-18.

25. Wehby, J., \& Lane, K. L. (2009). Proactive instructional strategies for classroom management. In A. AkinLittle, S. G. Little, M. A. Bray, \& M. J. Kehle (Eds.), Behavioral intervention in schools, evidence-based positive strategies (pp. 141-156). Washington, DC: American Psychological Association.

26. Williamson, K., Archibald, A., \& McGregor, J. (2010). Shared vision: A key to successful collaboration? School Libraries Worldwide, 16(2), 16-30.

27. Young, A., \& Kaffenberger, C. (2011). The beliefs and practices of school counselors who use data to implement comprehensive school counseling programs. Professional School Counseling, 15(2), 67-76. 


\section{APPENDIX A: CASE STUDY}

\section{Case Study}

Erika is a 12-year-old, Latina female in sixth grade, living with her father. Erika has not been completing her homework and does not always have school supplies. She is failing all of her core classes except math. She is generally very shy and quiet. Teachers report that she is usually inattentive in the morning and more attentive in the afternoon.

\section{APPENDIX B: COLLABORATION TEMPLATE}

\begin{tabular}{|c|c|}
\hline \multicolumn{2}{|c|}{ Collaboration Template for Student Success } \\
\hline \multirow{2}{*}{$\begin{array}{ll} & \text { Proactive } \\
\text { - } & \text { Planning }\end{array}$} & \multirow{2}{*}{ I will... } \\
\hline & \\
\hline - $\quad$ Schedule & \\
\hline - Map out & \\
\hline \multirow{2}{*}{\multicolumn{2}{|c|}{$\begin{array}{c}\text { Collaborate } \\
\qquad \quad \text { Partner }\end{array}$}} \\
\hline & \\
\hline \multicolumn{2}{|l|}{ - Co-Teach } \\
\hline \multicolumn{2}{|l|}{ - $\quad$ Consult } \\
\hline \multirow{2}{*}{\multicolumn{2}{|c|}{$\begin{array}{ll}\text { Data } & \\
\bullet & \text { Questionnaire }\end{array}$}} \\
\hline & \\
\hline \multicolumn{2}{|l|}{ - $\quad$ Interest inventory } \\
\hline \multicolumn{2}{|l|}{ - $\quad$ Observation notes } \\
\hline \multicolumn{2}{|l|}{ Analysis } \\
\hline \multicolumn{2}{|l|}{ - Interpret } \\
\hline \multicolumn{2}{|l|}{ - $\quad$ Find Patterns } \\
\hline - $\quad$ Predictors/Triggers & \\
\hline
\end{tabular}

